\title{
Preface to the 2006 Pingtung Earthquake Doublet Special Issue
}

\author{
Kuo-Fong Ma and Wen-Tzong Liang
}

Citation: Ma, K. F. and W. T. Liang, 2008: Preface to the 2006 Pingtung earthquake doublet special issue. Terr. Atmos. Ocean. Sci., 19, I-III, doi: 10.3319/TAO.2008.19.6.I(PT)

On 26 December 2006, two closely linked earthquakes, both $\mathrm{M}_{\mathrm{L}}$ 7.0, occurred only 8 minutes apart at 12:26:21 and 12:34:15 UT, respectively, in southwestern offshore of Taiwan near Pingtung. These two earthquakes were referred to as the Pingtung Earthquake Doublet that is unique not only because of being an earthquake doublet, but also both events were the largest in southwestern Taiwan during the past one hundred years. The occurrence of this doublet was in a region, where the seismic activity has been relatively low. According to the Central Weather Bureau (CWB) catalog, the epicenter of the first event is located at $21.69^{\circ} \mathrm{N}$ and $120.56^{\circ} \mathrm{E}$ with a focal depth $44 \mathrm{~km}$ and a magnitude of $\mathrm{M}_{\mathrm{L}}=7.0\left(\mathrm{M}_{\mathrm{w}}=7.0\right.$ Global CMT), the second earthquake was at $21.97^{\circ} \mathrm{N}$ and $120.42^{\circ} \mathrm{E}$, about $36 \mathrm{~km}$ to the northnortheast of the first event, with a magnitude of $\mathrm{M}_{\mathrm{L}}=7.0$ $\left(\mathrm{M}_{\mathrm{w}}=6.9\right.$ Global CMT $)$ and a focal depth of $50 \mathrm{~km}$. This earthquake doublet caused 44 injuries, including 2 fatal ones, 3 building collapses, and a massive failure of submarine communication cables, resulting in a significant economic loss. In addition, the Taipower's Nuclear Power Plant No. 3 (NPP3), which is within about $50 \mathrm{~km}$ from the epicenters of the earthquake doublet, registered the largest motions ever since the strong-motion recording commenced at the plant site. As a result, the Unit 2 of NPP3 was shut down while Unit 1 remained operatal at the time of the doublet event.

The occurrence of this earthquake doublet has caused a debate on the possible association to an active fault, and its linkage to the subducting slab of Manila trench. The focal mechanisms determined from Broadband Array in Taiwan for Seismology (BATS) were a normal faulting for the first, and a strike-slip faulting for the second event. The associated rupture planes of the earthquake doublet were difficult to determine due to the sparse distribution of the aftershocks for the first one. The aftershock distribution from the CWB near the hypocentral area of the second one suggests a west-dipping northwest-southeast striking ruptured plane. Tectonically, this earthquake doublet gives the insight toward understanding of the seismic activity in southwestern Taiwan, and thus, brings special attention to the potential hazard from large earthquakes in southern Taiwan. In view of the characteristics of the earthquake doublet, in this Special Issue, we have compiled valuable data observed from this earthquake doublet and studies investigating earthquake occurrence and rupture characteristics of this earthquake doublet. We believe that this Special Issue should be a useful documentation to the Pintung earthquake doublet, and will be beneficial to the hazard mitigation of the future large earthquakes associated with the southwestern Taiwan tectonics.

This Pingtung Earthquake Doublet Special Issue consists of 16 regular articles and 2 notes. It began with three articles on the discussion of the initial rupture of the earthquake by Haung et al. (2008a), the fault rupture plane determination and spatial slip distribution analysis from the regional strong motion and BATS waveform data by Lee et al. (2008) and Yen et al. (2008) to obtain the geometry of fault ruptures and to discuss the interaction of the earthquake doublet from the spatial slip distributions based on teleseismic data. Chen et al. (2008d) used the teleseismic data to refine the source depths of this earthquake doublet. Furthermore, Lin et al. (2008) studied the possible static triggering of earthquake doubles in convergent zones of Taiwan. The valuable strong motion data from the CWB's Taiwan Strong-Motion Instrumentation Program (TSMIP) stations for this earthquake doublet was compiled by four articles. The most comprehensive one is by Wu et al. (2008a), giving the data processing procedures for the efficient use of the data for other researchers, and a comparison of ground motions recorded by multiple accelerographs at a common site in Taipei, and attenuation of the horizontal ground motions. Wen et al. (2008) compiled the damage features and strong motion records, especially near the Taipower's Nuclear Power Plant No. 3, to give the seismic hazard assessment for southwestern Taiwan. Chen et al. (2008b) gave special attention to the long-period ground motion observations along paths of the earthquake doublet traversing the Central Range, and the Longitudinal Valley, respectively. Lee and Tsai (2008), furthermore, provided the near site structure for mapping average shear-wave velocity of the upper 30 meters of soil profile (Vs30) in Taiwan. In addition to seismic data, GPS observations and analysis associated with this earthquake doublet were also carried out by Chen et al. (2008a).

For offshore large earthquakes, several articles address their corresponding tsunami potential and the possible association of the earthquake doublet with the offshore tectonic structure. Chen et al. (2008c) evaluated the earthquake probabilities and energy characteristics in southwestern offshore Taiwan for the slow tsunami earthquake, and Wu et al. 
(2008b) further gave the numerical simulation of the tsunamis excited by the earthquake doublet. Chang et al. (2008) collected the seismic data recorded by the Ocean Bottom Seismic (OBS) Array in southwestern Taiwan priori to the occurrence of the earthquake doublet to give a background tectonic structure. Liao et al. (2008) employed the onshore data and temporary OBS array data, which was deployed soon after the occurrence of the earthquake doublet, to catch the aftershocks for the seismic tomographic studies off southwestern Taiwan.

Two articles related to the possible earthquake precursors of the doublet: Wu et al. (2008c) using Pattern Informatics (PI) analysis to address the precursory seismic activation of the Pingtung earthquakes, and Liu et al. (2008) reporting the Seismo-Ionospheric precursors to the earthquake doublet. Two notes on observations of the Taipei Basin Broadband Downhole Seismic network by Huang et al. (2008b) and the telecommunication cable failure from turbidity currents and submarine landslides induced by the earthquake doublet by Hsu et al. (2008) were also included. In addition to the published papers of this Special Issue, a large volume of valuable data and results associated with these papers were also collected and documented in a DVD and an online page (http://tecdc.earth.sinica.edu.tw/data /EQ2006Pingtung), hopefully beneficial to future studies as well as to the community for better understanding of the seismic hazard in southwestern offshore Taiwan.

\section{REFERENCES}

Chang, E. T. Y., S. K. Hsu, and C. S. Lee, 2008: Earthquake swarm recorded by an ocean bottom seismic array in southwest offshore of Taiwan in October, 2005. Terr. Atmos. Ocean. Sci., 19, 717-728, doi: 10.3319/TAO.2008. 19.6.717(PT).

Chen, H. Y., J. C. Lee, L. C. Kuo, S. B. Yu, and C. C. Liu, 2008a: Coseismic surface GPS displacement and ground shaking associated with the 2006 Pingtung earthquake doublet, offshore southern Taiwan. Terr. Atmos. Ocean. Sci., 19, 683-696, doi: 10.3319/TAO.2008.19.6.683(PT).

Chen, K. C., J. H. Wang, and T. L. Teng, 2008b: Long-period ground motion observations along two linear profiles from the 26 December 2006 Pingtung offshore earthquakes. Terr. Atmos. Ocean. Sci., 19, 653-669, doi: 10.3319/ TAO.2008.19.6.653(PT).

Chen, P. F., A. V. Newman, T. R. Wu, and C. C. Lin, 2008c: Earthquake probabilities and energy characteristics of seismicity offshore southwest Taiwan. Terr. Atmos. Ocean. Sci., 19, 697-703, doi: 10.3319/TAO.2008.19.6.697(PT).

Chen, Y. R., Y. C. Lai, Y. L. Huang, B. S. Huang, and K. L. Wen, 2008d: Investigation of source depths of the 2006 Pingtung earthquake sequence using a dense array at teleseismic distances. Terr. Atmos. Ocean. Sci., 19, 579-588, doi: 10.3319/TAO.2008.19.6.579(PT).
Hsu, S. K., J. Kuo, C. L. Lo, C. H. Tsai, W. B. Doo, C. Y. Ku, and J. C. Sibuet, 2008: Turbidity currents, submarine landslides and the 2006 Pingtung earthquake off SW Taiwan. Terr. Atmos. Ocean. Sci., 19, 767-772, doi: 10.3319/TAO. 2008.19.6.767(PT).

Huang, B. S., Y. L. Huang, S. J. Lee, Y. G. Chen, and J. S. Jiang, 2008a: Initial rupture processes of the 2006 Pingtung earthquake from near source strong-motion records. Terr. Atmos. Ocean. Sci., 19, 547-554, doi: 10.3319/TAO.2008. 19.6.547(PT).

Huang, W. G., B. S. Huang, K. C. Chen, C. C. Liu, C. R. Lin, S. H. Tsao, Y. C. Hsieh, and C. H. Chen, 2008b: Observations using the Taipei Basin broadband downhole seismic network: The 26 December 2006, Pingtung earthquake doublet, Taiwan. Terr. Atmos. Ocean. Sci., 19, 761-766, doi: 10.3319/TAO.2008.19.6.761(PT).

Lee, C. T. and B. R. Tsai, 2008: Mapping Vs30 in Taiwan. Terr. Atmos. Ocean. Sci., 19, 671-682, doi: 10.3319/TAO.2008. 19.6.671(PT).

Lee, S. J., W. T. Liang, and B. S. Huang, 2008: Source mechanisms and rupture processes of the 26 December 2006 Pingtung earthquake doublet as determined from the regional seismic records. Terr. Atmos. Ocean. Sci., 19, 555-565, doi: 10.3319/TAO.2008.19.6.555(PT).

Liao, Y. C., S. K. Hsu, C. H. Chang, W. B. Doo, M. Y. Ho, C. L. Lo, and C. S. Lee, 2008: Seismic tomography off SW Taiwan: A joint inversion from OBS and onshore data of 2006 Pingtung aftershocks. Terr. Atmos. Ocean. Sci., 19, 729-741, doi: 10.3319/TAO.2008.19.6.729(PT).

Lin, C. H., Y. H. Yeh, M. Ando, K. J. Chen, T. M. Chang, and H. C. $\mathrm{Pu}, 2008$ : Earthquake doublet sequences: Evidence of static triggering in the strong convergent zones of Taiwan. Terr. Atmos. Ocean. Sci., 19, 589-594, doi: 10.3319/TAO. 2008.19.6.589(PT).

Liu, J. Y., S. W. Chen, Y. C. Chen, H. Y. Yen, C. P. Chang, W. Y. Chang, L. C. Tsai, C. H. Chen, and W. H. Yang, 2008: Seismo-ionospheric precursors of the 26 December 2006 M 7.0 Pingtung earthquake doublet. Terr. Atmos. Ocean. Sci., 19, 751-759, doi: 10.3319/TAO.2008.19.6.751(PT).

Wen, K. L., Y. W. Chang, C. M. Lin, H. J. Chiang, and M. W. Huang, 2008: Damage and ground motion of the 26 December 2006 Pingtung earthquakes, Taiwan. Terr. Atmos. Ocean. Sci., 19, 641-651, doi: 10.3319/TAO.2008.19.6. 641(PT).

Wu, C. F., W. H. K. Lee, and D. M. Boore, 2008a: Strongmotion data from the two Pingtung, Taiwan, earthquakes of 26 December 2006. Terr. Atmos. Ocean. Sci., 19, 595-639, doi: 10.3319/TAO.2008.19.6.595(PT).

Wu, T. R., P. F. Chen, W. T. Tsai, and G. Y. Chen, 2008b: Numerical study on tsunamis excited by 2006 Pingtung earthquake doublet. Terr. Atmos. Ocean. Sci., 19, 705-715, doi: 10.3319/TAO.2008.19.6.705(PT).

Wu, Y. H., C. C. Chen, and J. B. Rundle, 2008c: Precursory seismic activation of the Pingtung (Taiwan) offshore doublet earthquakes on 26 December 2006: A pattern informatics analysis. Terr. Atmos. Ocean. Sci., 19, 743-749, 
doi: 10.3319/TAO.2008.19.6.743(PT)

Yen, Y. T., K. F. Ma, and Y. Y. Wen, 2008: Slip partition of the 26 December 2006 Pingtung, Taiwan (M 6.9, M 6.8) earthquake doublet determined from teleseismic waveforms. Terr. Atmos. Ocean. Sci., 19, 567-578, doi: 10.3319/ TAO.2008.19.6.567(PT).

\section{Responsible Editor:}

Chiou-Fen Shieh

Institute of Seismology and Applied Geophysics, National Chung-Cheng University

E-mail: seifent@eq.ccu.edu.tw

\section{Guest Editor:}

Wen-Tzong Liang

Institute of Earth Sciences, Academia Sinica

E-mail: wtl@earth.sinica.edu.tw

\section{Executive Guest Editor:}

Kuo-Fong Ma

Department of Earth Sciences and Institute of Geophysics, National Central University

E-mail: fong@earth.ncu.edu.tw 